\title{
Optimization of fed-batch fermentation for organic solvent tolerant and thermostable lipase production from recombinant E. coli
}

\begin{abstract}
Objective: Lipases are industrially important enzymes especially the thermostable and organic solvent tolerant lipases. This study was planned to enhance the production using fed batch fermentation technique. Materials and Methods: The possibility of using fed-batch fermentation for improvement of organic solvent tolerant and thermostable lipase production by recombinant E.coli BL21 was studied in $2 \mathrm{~L}$ stirred tank bioreactor. Exponential fed-batch fermentations were operated at different specific growth rates $(\varepsilon)$. The effect of antibiotics addition in feed medium, on the number of plasmid bearing cells was also investigated. Kinetics of the fed-batch fermentation was evaluated for the generation of kinetic parameter values. Effect of yeast extract in feed medium was also investigated. Results: The number of plasmid bearing cells was increased from $13 \%$ to $91 \%$ with the addition of antibiotics ( $2 \mathrm{~g} / \mathrm{L}$ ampicillin and $1.4 \mathrm{~g} / \mathrm{L}$ chloramphenicol) in the feed medium. Among the different $\varepsilon$ investigated $(0.05,0.10$ and $0.15 \mathrm{~h}-1)$, the highest cell concentration $(30.32 \mathrm{~g} / \mathrm{L})$ and lipase production $(130.5 \mathrm{IU} / \mathrm{mL})$ were obtained in exponential fed-batch fermentation, where $\varepsilon$ was controlled at $0.10 \mathrm{~h}-1$ with $800 \mathrm{~g} / \mathrm{L}$ glucose in the feed medium. No significant improvement was achieved on growth and lipase production in fed-batch fermentation with addition of yeast extract in feed medium, though $\varepsilon$ was controlled at 0.10 h-1. Conclusion: Fed-batch was found a good technique for enhancement of lipase production from recombinant E.coli BL21 on the cost of increasing time of fermentation (fermentation time for batch fermentation was $16 \mathrm{~h}$ and for fed-batch was $26 \mathrm{~h}$ ) and quantity of some medium ingredients as compared to the batch mode.
\end{abstract}

Keyword: E.coli; Fed-batch culture; Recombinant; Thermostable lipase 